\title{
The New Strategy: Collaboration between Enterprise and Nonprofit Organization
}

\author{
Xueying TIAN \\ Tongji University, Shanghai, China
}

\begin{abstract}
Under the circumstances of globalization, collaboration between organizations becomes an important topic in the field of strategy management. With an increase of nonprofit organization in scale and number, it has been a new choice that enterprise builds collaborative relationship with nonprofit organization. Considering the different characteristic of two organizations, this paper begins with different motives of collaboration between enterprise and nonprofit organization and then explores many kinds of modes of collaboration. By describing the social embeddedness of organization behavior, this paper sets forth the concept and formation mechanism of collaborative network. Future research on collaboration between enterprise and nonprofit organization would be strengthened in effect and management of collaboration based on network theory.
\end{abstract}

Keywords: collaboration, nonprofit organization (NPO), motive, mode, collaborative network

\section{1 引言}

隨著經濟全球化和科學技術的迅猛發展, 越來越 多的企業開始認識到, 單憑企業自身的力量很難在競 爭激烈的市場環境中求得生存和發展。20 世紀 80 年 代以來, 西方企業尤其是跨國企業迫於強大的競爭壓 力, 開始對企業競爭關係進行戰略性的調整, 紛紛從 對立競爭走向大規模的合作競爭, 也因此使得合資、 戰略聯盟等組織形式成為了諸多企業用來實現資源和 戰略共用而實施的核心戰略[1]。近年來, 作為社會領 域的重要組織形式, 非營利組織 (行業協會、醫院、 大學、社團等) 迅速成長起來, 日益成為了一股重要 的社會力量[2], 這顯著地改變了企業面臨的生存條件 和發展環境。因而, 企業如何與非營利組織建立合作 以獲得共同發展成為必須給予高度關注的問題。

誠然, 當前的戰略管理文獻對合作、聯盟等現象 給予了很多的關注, 但是大多考慮同一部門內部的組 織間合作, 並且主要是企業之間的戰略聯盟關係[3], 有關企業與非營利組織之間的跨部門合作與聯盟並沒 有得到應有的重視[4]。而由於非營利組織特殊的社會 屬性(志願性、非營利性、公益性等) 決定了它們與一 般企業在組織結構、治理機制、組織文化和組織使命 等方面存在根本性差異, 因此, 無法將企業戰略聯盟 理論的研究成果直接推廣應用到企業與非營利組織合 作這種特殊的關係[5]。已有的戰略聯盟理論無法解釋 企業與非營利組織之間的這種新型合作形態, 從而制
約了理論對實踐活動的指導作用。因此如何借鑒企業 戰略聯盟理論的研究思路, 充分考慮企業與非營利組 織的不同組織特徵, 進而對企業與非營利組織合作發 展以獲得雙贏進行探討是值得深入研究的領域。

本文首先從企業和非營利組織的不同視角分析了 合作的動因, 並歸納了七種不同的合作類型, 進而基 於嵌入性觀點闡釋了企業與非營利組織合作網路的構 建機制，最後指出基於網路理論探討合作的動因、類 型、績效和治理, 對我國企業與非營利組織合作實踐 的指導意義。

\section{2 合作的動因}

可以看出, 企業和非營利組織是基於一定的某一 類型的關係而相互聯結而進行合作的, 那麼, 這種合 作的動因又是什麼呢? 對於這一問題, 湯普森曾給出 了互倚性或互依性（interdependence）[6]概念, 以表 明合作的動因, 即, 企業和非營利組織之間存在著一 定的相互依賴、相互作用的需求, 這樣才能保證它們 之間彼此的聯結而形成合作。借鑒霍基和安索利教授 對企業間建立關係的動機的研究，筆者從企業與非營 利組織不同視角, 對合作的具體動因予以歸納, 如圖 1 所示:

\section{1 企業視角}

1) 高收益成本比。“成本一收益比” 意味著經 


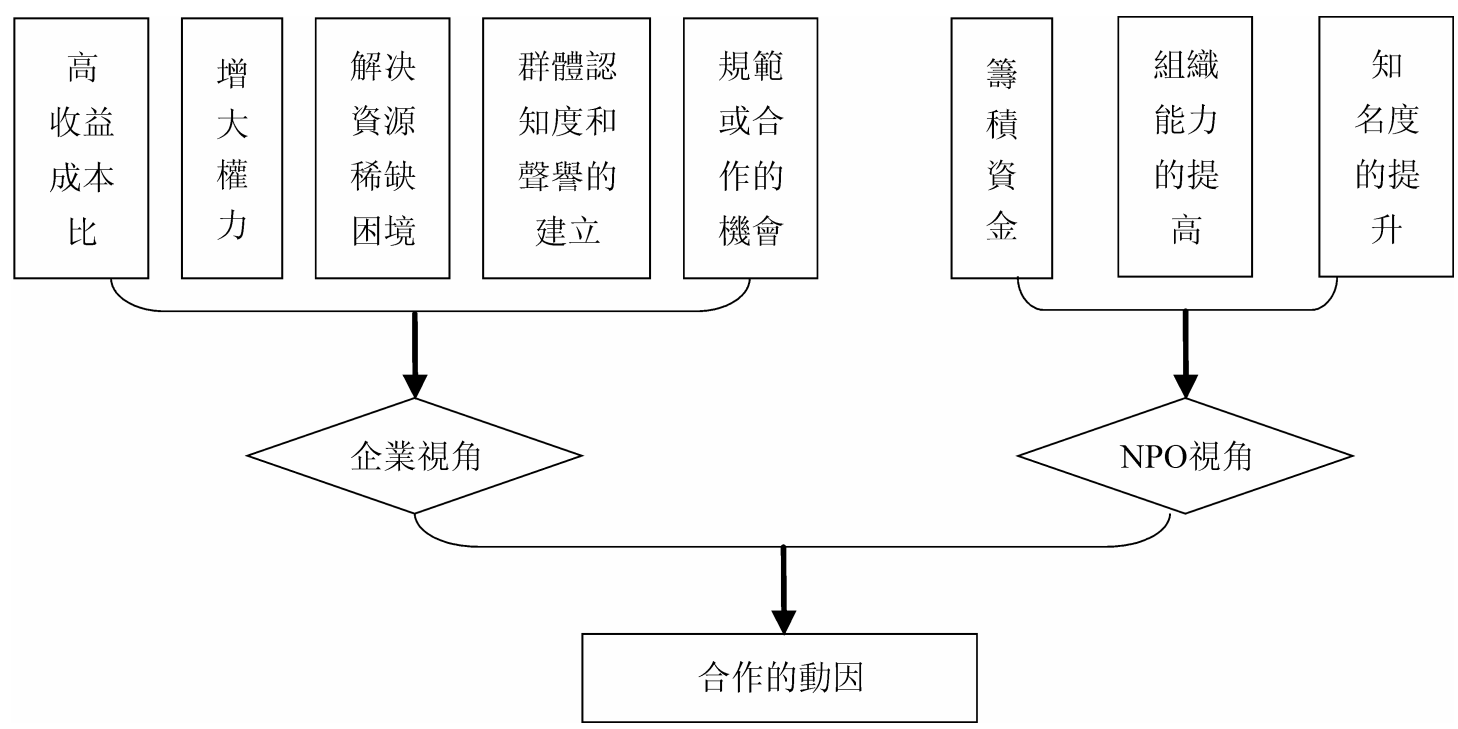

圖 1. 企業與非營利組織合作的動因

Figure 1. Motive of collaboration between enterprise and nonprofit organization

濟單位進行經濟活動時, 要進行成本與收益的比較, 當成本小於收益時, 有利可圖, 可以進行此項經濟活 動; 反之, 則不進行此項經濟活動。企業在與非營利 組織建立合作關係時, 需要做出一定的犧牲, 如要貢 獻出某些資源, 或放棄一定的自主權等, 當然, 它也 會從中受益。當收益大於成本時, 就有進行合作的可 能。

2) 增大權力。一個企業組織如果通過與非營利組 織建立某種合作關係, 可以使它在環境中獲得更大的 權力, 這也會促使它去建立這種聯繫。如企業可以以 捐贈者身份擔任非營利組織或其所組織的活動中的顧 問、理事等職務而獲得一定的參與公共事務決策的權 力。

3) 解決資源稀缺困境。這一點不難理解, 當一個 企業難以獲得所需要的資源或者難以實現其目標時, 它就會尋求其他組織, 試圖建立合作關係, 這樣既可 增大權力又可分享稀缺資源。這也是中小企業在資源 稀缺的情況下, 與非營利組織構建合作關係以獲得成 長的一種方法。

4) 群體認知度和聲譽的建立。在激烈的市場競爭 中, 承擔社會責任已經成為企業體現社會道德而獲取 經濟利益的一種有效方式。非營利組織的活動和行為 體現著社會誠信與社會公益。企業若以擴大群體認知 度和建立企業聲譽為目標, 與非營利組織相關聯而共 同開展公益活動, 構建穩定的合作關係, 則是實現社 會責任的最佳途徑。

5) 規範或合作的機會。當外在環境的規範支援組 織間的活動或存在著企業與非營利組織合作的契機
時, 相互合作更容易形成, 尤其是當企業曾經有過成 功的歷史, 非營利組織具有良好的社會公信力時, 它 們就可能更傾向于相互之間建立合作關係。

\section{2 非營利組織視角}

1) 籌集資金。非營利組織的資金主要來源於政府 的財政撥款，但是近年來，政府的財政撥款日益減少。 同時由於 “非營利性”、“公益性” 等特點, 大部分非 營利組織缺乏自營收入; 加之, 源於傳統籌資觀念和 組織目標和宗旨之間的衝突, 非營利組織雖然處於市 場環境中，但在籌資運作方面卻沒有運用市場化的管 道。面臨著生存困境, 尋找新的籌資來源迫在眉睫。 而營利性領域無疑是最具前景的資金來源。基於這一 動因，非營利組織有與企業合作的可能。

2) 組織能力的提高。專業管理人才和志願者的缺 乏, 致使非營利組織組織能力低下, 效率不高, 這已 經成為制約非營利組織發展的一個重要因素。營利性 領域則擁有豐富的人力資源和較高的組織管理能力, 非營利組織與企業建立合作網路，不僅可以從中獲取 大量的優秀人才，而且有機會向企業學習先進的管理 經驗和方法, 從而可以提高自身的組織能力, 較好地 完成組織的使命。這是促使非營利組織與企業形成合 作關係的重要動因。

3) 知名度的提升。作為社會領域中的重要部門, 非營利組織要在群體當中建立良好的社會公信力, 必 須要以提升社會知名度為前提。通過與成功的企業共 同參與社會公益而建立合作關係，非營利組織不僅可 以獲得口碑效應，而且可以借助企業的宣傳，贏得更 
多的社會關注, 提升知名度, 從而有利於社會公信力 的建立。

\section{3 合作的類型}

從 20 世紀 80 年代後期開始, 西方學者主要從市 場行銷學的角度對企業與非營利組織的合作方式進行 了分類[7]; 。進入 21 世紀以後, 隨著企業與非營利組 織的合作在內容和形式上的不斷延伸與拓展, 眾多的 學者開始從戰略管理的視角來審視這種跨部門的合作 關係[8]。

Andreasen（1996）提出了企業與非營利組織合作 的三種方式,即與業務關聯的公益推廣活動、共同主題 行銷和核發許可證方式的行銷[7]。Wymer 和 Samu （2003）將企業與非營利組織的聯盟方式概括為七種 類型：企業慈善、企業基金、許可證協定、贊助、基 於交易的推廣、共同主題推廣及聯合經營[8]。此外, 他們從聯盟的管理、動機、承諾和風險四個方面對這 七種聯盟形式進行了分析, 識別出以下兩個關鍵特徵 維度:（1）利益關注焦點;（2）權力控制源。其中,

“利益關注焦點” 是指在企業與非營利組織的聯盟關 係中, 企業尋求自身利益與促進非營利組織事業的對 比度。“權力控制源” 是指在企業與非營利組織的聯盟 關係中，企業與非營利組織的控制權對比。（如圖 2)

這種分類方式不但可以表明企業與非營利組織的 各種聯盟形式如何按照上述兩個特徵維度進行區分, 而且可以指導管理者結合自己的目標來選擇合適的合 作類型 [8]。例如, 管理者首先明確其目標, 然後決定 所期望達到的商業回報水準。一旦確定了想從合作關 係中獲得的相對回報比率, 他們就可以決定期望維持 的控制水準。如果管理者無法找到與期望回報和控制 權相對應的合作關係, 這就意味著他們必須根據上述 兩個關鍵特徵維度來調整期望值[5]。

基於上述分析，筆者將企業與非營利組織合作的 類型劃分為以下七種:

1) 企業慈善或企業捐贈。企業慈善是企業在一定 時期內對非營利組織進行一些貨幣性或非貨幣性（實 物、技術等) 捐贈, 企業旨在支援非營利組織達成使 命, 也包括允許雇員志願參加非營利組織。

2) 企業基金。企業基金是企業創立的管理慈善目 標的非營利實體, 這種類型的企業投入強調非營利的 使命, 企業合作方通過它的代理人保持對基金的控制, 例如福特基金。

3) 活動贊助。活動贊助是指企業為在非營利活動 中使用企業的品牌支付非營利組織的贊助費。在贊助 活動中, 企業的主要興趣在於提升其品牌。贊助類型 很多, 包括運動贊助、圖書贊助、展覽贊助、教育贊
助、文化活動、地方事件等。

4) 共同主題推廣 (合作推廣)。在這種合作關係 中, 企業與一個或多個非營利組織達成協定, 通過分 發產品和宣傳資料以及做廣告等方式, 共同解決某個 社會問題[9]。雙方之間可能有資金流通，也可能沒有。 比較典型的例子是上海交大昂立股份有限企業。該企 業通過與上海市紅十字會、上海市健康教育所等數十 家單位建立的緊密合作的關係, 自 1993 年以來, 每 年有持續半年的時間在各區域市場開展科普活動, 向 公眾宣傳科學保健知識, 同時也使得消費者產生對產 品的潛在需求, 這種持久的親和力直接拉動了市場的 消費。

5) 與業務關聯的公益推廣（基於交易的推廣）。 在這種合作類型中，企業將銷售收入的一定比例（通 常有上限）以現金、實物或設備的形式捐贈給非營利 組織[9]。為人熟知的例子是農夫山泉企業, 宣稱每銷 售一瓶礦泉水，該企業就向希望工程捐款一分錢。

6) 許可證協議。非營利組織在收取一定的費用或 提取部分收入的條件下批准營利性企業使用其名稱和 商標。企業旨在從許可中增加銷量, 有許多的運作控 制。這種形式的出現早於 20 世紀 80 年代出現的扶助 公益事業的行銷形式。

7) 聯合經營。聯合經營是企業與原來的非營利對 手共同創立並經營新的非營利實體。主要由於企業發 現通過合作的形式支援非營利組織而不是反對他們, 可以產生更好的結果。這種形式最常見的是製造商與 環境組織的合作。

\section{4 合作網路的構建機制}

\section{1 合作網路的概念界定}

按照 Hakansson（1987）的觀點, 網路應該包括 三個基本的構成要素:行為主體、活動的發生和資源 [10]。其中, 行為主體不僅包括個人、企業或企業群, 而且在更廣的範圍上包括政府、仲介組織機構、教育 和培訓組織等; 網路中的活動包括網路中行為主體內 部知識、資訊等的傳遞活動、企業外部的交易活動、 企業內部的傳遞活動、聯接到企業外部的活動, 以及 整個網路中行為主體之間的資訊、知識、技術等資源 和生產要素的流動等相關活動; 而資源則包括物質資 源、金融資產和人力資源等。

通過對網路構成要素的分析可以發現, 網路的形 成是由於具有參與活動能力的行為主體, 在主動或被 動地參與活動過程中, 借助資源的流動, 形成了一些 彼此之間正式或非正式的關係總和。例如，在一個企 業的外部網路中, 既可以看到企業在與供應商、客戶 


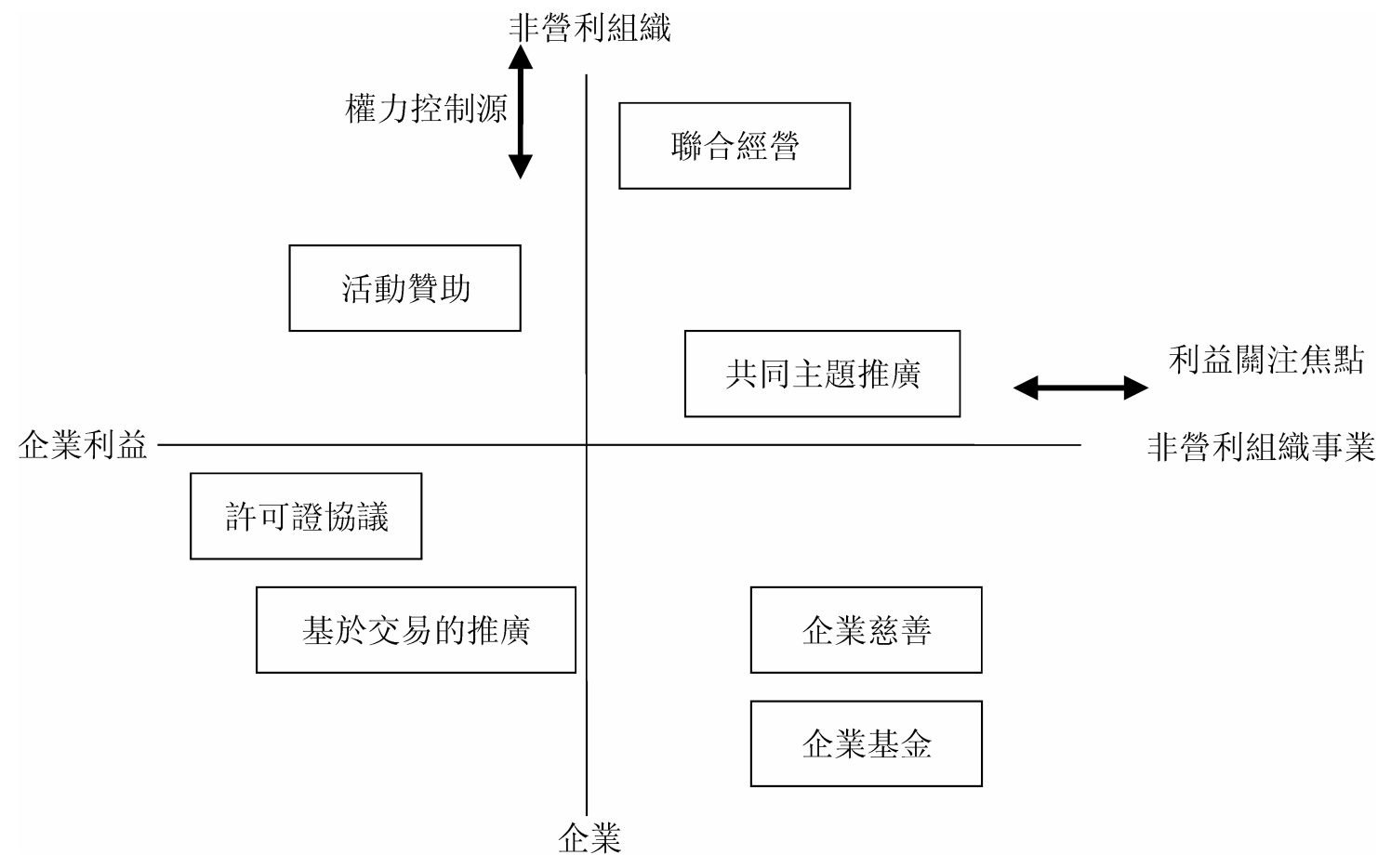

圖 2. 企業與非營利組織合作的二維分類圖[8]

Figure 2. Classification of collaboration between enterprise and nonprofit organization

交易過程中建立的產業價值鏈上的縱向關係, 又可以 看到企業與政府、非營利組織（如行業協會、大學或 研究機構）等仲介組織建立的横向關係等。所以, 從 微觀經濟學的角度來看, 結網在很大程度上是指企業 如何與輔助部門聯接, 供應商如何與客戶聯接, 區域 內的各種機構如何在研發活動中合作, 技術、資訊等 資源如何在各個經濟主體之間擴散等。因此, 從這一 意義上講, 合作網路就是企業與非營利組織之間在交 換資源、傳遞資源活動過程種發生聯繫時而建立的各 種關係總和，這些關係有時是基於共同的社會文化背 景和信任基礎上結成的非正式關係, 有時是發生在市 場交易或知諳、技術等創造過程中的正式合作關係。

因而, 可以這樣來定義企業與非營利組織合作網 路, 即: 相互獨立的企業和非營利組織在協同交互作 用中基於各種關係類型而相互關聯，所共同構成的一 種具有指向性的、穩定的合作聯結系統。該定義突出 了以下幾個要點: 首先, 合作網路是由一定數量規模 的企業和非營利組織構成的; 其次, 合作網路是企業 與非營利組織之間的, 屬於企業外部網路, 而非企業 內部的網路; 第三, 企業與非營利組織之間的合作是 有指向性的, 是穩定的; 第四, 企業與非營利組織之 間的聯結是基於某種關係類型而存在的。這種關係類
型可以是純粹經濟性的市場關係, 如企業與非營利組 織進行產品合作、管道合作; 也可以是社會性的社會 關係, 如企業的員工與非營利組織的志願者進行私下 討論和資訊交流。當然, 更一般的情形是二者的結合, 是社會網路與市場網路的疊加。

\section{2 合作網路的形成和結構}

持開放系統觀點的組織理論學者和結構社會學家 們很早就堅持認為, 組織環境中最重要的就是它外部 聯繫所構成的社會網路。他們強調, 經濟行為和其他 社會行為一樣, 不是孤立存在的, 而是深深地嵌入社 會網路之中[11]。社會網路可以定義成由一系列相互 聯繫的特定類型的社會關係結點所構成的集合。社會 關係可以是朋友關係、上下級關係, 也可以是純粹的 經濟關係等等[12]。這種觀點最終可以歸結為經濟行 為的社會嵌入性 (social embeddedness), 通過關係網 絡, 行動者可以獲得他們所需要的資源和資訊。嵌入 性是網路內主體間關係的本質特徵, 它促成網路的形 成, 並成為早期競爭優勢的來源。

企業與非營利組織雙方基於組織間的信任在交互 作用中形成了合作網路。從嵌入理論的觀點看, 經濟 行為是嵌入於社會結構中的, 而社會結構的核心就是 


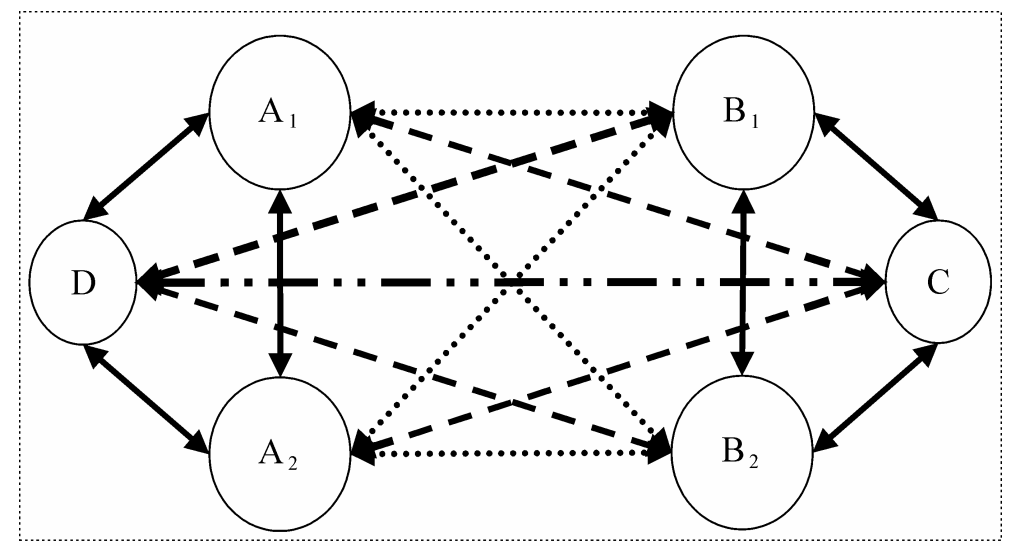

圖 3. 嵌入性紐帶與網路結構的形成

Figure 3. Formation of embedded connection and network structure

人們生活其中的社會網路。因此, 企業與非營利組織 所形成的合作網路與社會網路並不是截然分開、相互 無關的, 正確的理解應當是合作網路是嵌入于更為廣 大的社會網路之中的, 而嵌入的網路機制就是信任。 信任可以表示成對一個交易夥伴不會損人利已的信 心，這種信心的形成是啟發式的、把其他人動機和行 為假設為最好的偏好 [13]。由於信任來源於社會網路 且嵌入社會網路之中, 因此組織的經濟行為也嵌入於 社會網路的信任結構之中。合作網路使企業與非營利 組織可以通過相互間聯繫的紐帶來獲取資訊收益。

作為社會領域中的重要部門, 非營利組織必然在 履行社會職能的過程中與政府、社會群體以及其他社 會機構發生著千絲萬縷的聯繫。基於組織間信任的傳 遞[14], 合作網路中的企業, 與政府、社會群體、其 他社會機構得以接觸, 逐步建立緊密的紐帶, 形成嵌 入性連接。非營利組織就是企業網路嵌入社會網路的 節點, 發揮著傳遞信任、資訊及社會關係資源的橋樑 作用, 使得合作網路深深嵌入於社會網路之中。相應 的, 非營利組織與企業關聯機構之間的連接也會形成, 而企業的關聯機構與非營利組織的關聯機構也最終建 立了嵌入性連接。因此, 隨著嵌入性連接數量的不斷 增加, 網路關係也在不斷擴展。直至各個行為主體之 間都建立了嵌入性連接, (擴展的) 網路結構便呈現出 來。最終形成的網路結構可以用圖 3 進行表示。

圖中 A1、A2 代表企業, B1、B2 代表非營利組織, C 代表非營利組織的關聯機構和群體 (地方政府、社 會群體、其他機構), D 代表企業網路中的其他機構。 圖中實線分別代表企業網路和非營利組織網路。企業
與非營利組織之間通過信任機制建立聯結, 形成合作 網路, 由圖中圓點連接線表示。企業通過合作網路, 將非營利組織 B1、B2 作為節點, 與非營利組織的關 聯機構和群體 C 建立了聯繫 A1-C 和 A2-C, 同樣, 非營利組織也通過合作網路相應的將企業 A1、A2 作 為節點, 與企業相聯繫的機構 D 建立了聯結 B1-D 和 B2-D, 圖中以短劃線來表示。隨著聯結的增加和 信任的傳遞, $\mathrm{C}-\mathrm{D}$ 也建立了聯結, 最終, 社會網路 得以構成。企業與非營利組織的合作網路也通過這些 聯結而深深嵌入在整個社會網路之中。

\section{5 結語和研究啟示}

在激烈的市場競爭中, 原子主義行動者的假設已 經越來越與現實狀況不符。市場中的每個組織都嵌入 在一個社會的、文化的、經濟的網路之中, 與其他組 織發生著各種各樣的聯繫。網路研究將社會經濟活動 放到了更加現實和更為廣闊的背景下進行分析, 這不 僅使我們對社會行動者的行為動因有了更加全面而深 入的理解, 而且對於描述和分析宏觀層次上的集體行 為和長期選擇也有很強的說服力。因此, 以網路理論 為基礎閭釋組織間合作的績效及管理具有較強的解釋 能力。全球經濟一體化的複雜環境中, 企業與非營利 組織合作發展作為一種新戰略, 已經開始受到全社會 的廣泛關注。隨著我國改革開放步伐的加快, 我國企 業與非營利組織合作也具有更為重要的意義。由此, 基於網路理論, 深入研究我國市場經濟發展以及和諧 社會構建背景下的企業與非營利組織合作的動因、類 型、績效和治理等問題, 對於指導我國企業與非營利 
組織的合作實踐具有重要的價值。

\section{REFERENCES}

[1] Guo, J. G. and Gao, J., “M. Networks, resources and competitive sdvavtages: A firm-sociological view [J]," China Industrial Economy, No. 3, pp. 79-87, 2003.

[2] Tian, K., "The review on the west country theories of nonprofit organization [J],” Chinese Public Administration, No. 6, pp. 59-64, 2003.

[3] Das, T. K. and Teng, B. S., “A resource-based theory of strategic alliances [J],” Journal of Management, Vol. 26, No. 1, pp. 31-61, 2000.

[4] Googins, B. and Rochlin, S., "Creating the partnership society: Understanding the rhetoric and reality of cross-sectoral partnerships [J]," Business and Society Review, Vol. 105, No. 1, pp. 127-144, 2000.

[5] HU, Y. C., CAI, N., and TIAN, X. Y., "Research on the alliance between enterprise and nonprofit organization [J],” Foreign Economies and Management, Vol. 28, No. 10, pp. 11-17, 2006.

[6] Thompson, G., Frances, J., Levacic, R. and Mitchell, J., "Hierarchies and Networks: The Coordination of Social Life [M],” London: Stage, 1991.
[7] Andreasen and Alan, R., "Profits for nonprofits : Find a corporate partner [J],” Harvard Business Review, pp. 47-59, November/December 1996.

[8] Wymer, W. W. and Samu, S., "Dimensions of business and nonprofit collaborative relationships [J]," Journal of Nonprofit and Public Sector Marketing, Vol. 11, No. 1, pp. 3-22, 2003.

[9] YU, J. D., ZHAO, W. H., and WAN, D.F., "Discussion on the motivation, risk and control of alliance between nonprofit organization and enterprise [J]," Forecasting, Vol. 25, No. 2, pp. 44-48, 2006.

[10] Hakansson H., "Industrial Technological Development: A Network Approach [M],” London Press, 1987.

[11] Powell, W. W., "Neither market nor hierarchy: Network forms of organization [J]," Research in Organization Behavior, No. 12, pp. 295-336, 1990.

[12] Galaskiewicz, I. and Marsden, P., "Interorganizational resources networks: Formal patterns of overlap [J],” Social Science Research, Vol. 7, pp. 89-107, 1978.

[13] Uzzi B., "Social structure and competition in interfirm networks: The paradox of embeddedness [J]," Administrative Science Quarterly, Vol. 42, No. 1, 1997.

[14] Ghemawat P., "Commitment: The dynamic of strategy," Free Press, New York, 1991. 